\title{
Deteksi Kavitasi Pada Pompa Sentrifugal Menggunakan Spektrum Getaran dan Spektrum Envelope
}

\author{
(Cavitation Detection Method in Centrifugal Pump Using Vibration Spectrum and \\ Envelope Analysis)
}

Berli P KAMIEL, Deby ARIKH NASAKA, BAmbang RiyANTA, AZHIM ASYratul

\begin{abstract}
ABSTRAK
Kavitasi adalah salah satu indikator penting kondisi operasi sebuah pompa sentrifugal. Fenomena kavitasi ditunjukkan dengan terbentuknya formasi gelembung udara yang kemudian pecah secara tiba-tiba akibat perubahan tekanan pada sisi hisap pompa. Kavitasi dapat menyebabkan kerusakan yang parah komponen pompa terutama bagian sudu atau impeller. Kavitasi biasanya dapat diidentifikasi melalui suara bising dan timbulnya getaran yang berlebihan. Sebuah metode deteksi kavitasi dibutuhkan agar potensi kerusakan lebih lanjut pada pompa sentrifugal dapat diantisipasi secepatnya. Penelitian ini bertujuan menghasilkan sebuah metode deteksi kavitasi menggunakan spektrum getaran dan spektrum envelope pada bentang frekwensi rendah $0-4 \mathrm{kHz}$ dan bentang frekwensi tinggi 4-8,5 kHz. Sinyal getaran pompa direkam menggunakan sebuah akselerometer yang diletakkan pada rumah volute pompa arah aksial. Sinyal getaran kemudian ditransformasikan kedalam spektrum dan spektrum envelope menggunakan Fast Fourier Transform. Spektrum dan spektrum envelope untuk masing-masing bentang frekwensi dibandingkan antara pompa kondisi normal dan kondisi tiga level kavitasi kavitasi. Hasil penelitian menunjukkan bahwa spektrum frekwensi rendah dapat digunakan untuk mendeteksi kavitasi level 3 yang ditunjukkan dengan peningkatan amplitudo frekwensi poros sebesar 47,6 Hz dan 1/2 BPF sebesar 149,6 Hz. Sedangkan kavitasi level 1 dapat dideteksi oleh spektrum envelope pada bentang frekwensi tinggi. Dapat disimpulkan pula bahwa penurunan ampitudo teramati secara umum pada domain waktu seiring dengan meningkatnya level kavitasi.
\end{abstract}

Kata kunci: kavitasi, pompa sentrifugal, spektrum getaran, spektrum envelope, bentang frekwensi

\section{ABSTRACT}

Cavitation is an important indication of operation condition for a centrifugal pump. An indication of the appearance of cavitation is the formation of bubbles which collapse suddenly when the pressure changed on the suction side of the pump. The formation of cavitation bubbles can cause fault to the inner pump components. The fault that often results from cavitation phenomenon is affected in the impeller. This fault is usully identified through noise and vibration generated. Therefore, a method is needed to detect early cavitation phenomenon at the centrifugal pump. This study aims to develop cavitation detection methods using the vibration spectrum and envelope spectrum of low frequency band of $0-4 \mathrm{kHz}$ and high frequency band of 4 $\mathrm{kHz}-8,5 \mathrm{kHz}$. In this study, cavitation detection in conducted by recording vibration signals that occur at centrifugal pump using an accelerometer. The data obtained is then transformed into the frequency domain and envelope spectrum using Fast Fourier Transform. The results were compared between normal condition and level 1, 2, and 3 cavitation. Comparisons were made on each vibration spectrum and envelope spectrum at the low frequency and high frequency bands. The result of this study showed that the vibration spectrum with low frequency band can detect the formation of level 3 cavitation with an increase in shaft frequency amplitude (47,26 $\mathrm{Hz}$ ) and 1/2 BPF (149,6 Hz). Whereas early cavitation or level 1 cavitation was identified through the envelope spectrum at high frequency band. It also showed that 


\begin{abstract}
a decrease in amplitude occured gradually in the time domain along with increasing
\end{abstract} level of cavitation.

Keywords: cavitation, centrifugal pump, vibration spectrum, envelope spectrum, frequency band

\section{PENDAHULUAN}

Pompa merupakan mesin yang mengkonversikan energi mekanik menjadi energi kinetik. Pompa akan memberikan energi mekanis pada fluida, dimana energi yang diterima berguna untuk menaikkan tekanan pada saluran-saluran instalasi pompa (Yohana dkk, 2016). Pompa juga merupakan mesin aliran fluida yang berfungsi sebagai alat pemindah fluida dari satu tempat ke tempat lainnya dengan prinsip kerja membuat perbedaan tekanan pada sisi hisap (suction) dan sisi tekan (discharge).

Secara umum ada beberapa jenis pompa yang banyak digunakan dalam perindustrian, salah satunya adalah pompa sentrifugal. Pompa sentrifugal merupakan pompa jenis rotary yang menghasilkan tekanan dinamis sehingga dapat mengalirkan fluida dari tempat rendah ke tempat lebih tinggi. Saat ini pompa sentrifugal telah banyak digunakan oleh industri pengolahan dan pendistribusian. Namun dalam penggunaannya sering sekali didapati pompa mengalami penurunan perfoma sampai pada akhirnya terjadi kerusakan. Kasus kerusakan yang sering terjadi yaitu, korosi, kerusakan rumah volute, kebocoran seal, sampai rusak pada impeller (Albraik, 2004). Penyebab dari kerusakan yang terjadi pada pompa sentrifugal sangatlah beragam, akan tetapi faktor penyebab kerusakan yang umumnya terjadi pada pompa terutama komponen bagian dalam adalah akibat dari kavitasi.

Kavitasi merupakan pembentukan rongga kosong dalam suatu cairan dan kemudian pecah secara tiba-tiba. Kavitasi terjadi ketika fluida cair berada pada daerah yang mengalami perubahan tekanan dengan cepat. Fenomema ini sangat berbahaya dan diketahui sebagai fenomena yang bersifat merusak pada bagianbagian penting komponen pompa dan dapat menurunkan performa pompa. Dalam hal kavitasi, bagian pompa yang sering mengalami kavitasi adalah sisi isap pompa. Hal ini terjadi karena tekanan isap pompa terlalu rendah hingga dibawah tekanan uap jenuh (Isranuri dan Irwansyah, 2012).
Kavitasi dapat terbentuk ketika tekanan pada sistem perpipaan atau pompa mengalami penurunan nilai kurang dari tekanan uap jenuh pada suhu titik operasi tertentu. Fluida yang mengalir melalui pompa dapat membentuk gelembung uap (Avellan, 2004). Gelembung ini kemudian pecah secara tiba-tiba di tempat yang memiliki tekanan lebih tinggi.

Pompa yang sedang beroperasi dalam kondisi kavitasi akan menimbulkan suara bising akibat dari getaran yang terjadi karena terbentuknya gelembung air yang kemudian pecah secara terus menerus. Kondisi ini apabila dibiarkan akan menyebabkan kerusakan mekanis pada komponen pompa. Kerusakan yang sering terjadi akibat kavitasi adalah terbentuknya lubang-lubang korosi pada impeler maupun casing pompa (Soyama dkk, 1992).

Terdapat beberapa metode yang digunakan untuk mengamati kavitasi dini. Menurut Puoya dkk. (2017) pompa sentrifugal yang mengalami kondisi kavitasi akan menghasilkan sinyal khusus seperti getaran, tekanan, dan emisi akuistik. Namun dalam mendeteksi kavitasi pada pompa, metode yang paling populer digunakan adalah metode berbasis sinyal getaran (Contreras dkk, 2002). Melalui metode ini, spektrum getaran dapat digunakan untuk mendeteksi kavitasi melalui observasi amplitudo pada frekwensi tertentu.

Berdasarkan metode penelitian yang telah dilakukan sebelumnya, Al-Hashmi (2004) menggunakan metode untuk mendeteksi kavitasi pada pompa sentrifugal dengan metode spektrum getaran. Metode ini berdasarkan pada perbandingan amplitudo getaran dengan laju aliran pompa memiliki kesesuaian dengan karakteristik getaran yang ditimbulkan akibat fenomena kavitasi. Melalui hasil yang diperoleh dari spektrum getaran deteksi kavitasi dapat diukur dari nilai standar deviasinya.

Penelitian Zouari dkk. (2004) mendeteksi kavitasi yang terjadi pada pompa sentrifugal menggunakan spektrum getaran. Melalui spektrum getaran, deteksi kavitasi dapat diamati dari peak tinggi yang muncul pada bentang frekwensi tertentu. Hasilnya menunjukkan akurasi deteksi yang benar antara 98-100\%. Hasil tersebut menunjukkan fenomena kavitasi 
dapat dideteksi secara langsung dari spektrum getaran.

Sedangkan penelitian yang telah dilakukan oleh Farhat (1996) memberikan pernyataan bahwa fenomena kavitasi pada pompa akan lebih mudah dideteksi dengan sinyal getaran berbasis analisis envelope. Kaye (2000), memantau kavitasi pada pompa sentrifugal menggunakan analisis getaran, dimana viabilitas atau kemungkinan terjadinya kavitasi dapat diamati dari hasil yang ditunjukkan oleh analisis envelope. Klasifikasi kavitasi pada pompa sentrifugal yang telah dilakukan oleh Kaye dan Farhat (2003) menyatakan bahwa analisis envelope adalah cara yang paling tepat untuk mendeteksi dan mengukur kavitasi pada pompa.

Penelitian sebelumnya telah mengaplikasikan metode spektrum getaran dan spektrum envelope pada keseluruhan bentang frekwensi. Hasilnya menunjukkan bahwa metode spektrum getaran dan spektrum envelope dapat digunakan untuk mendeteksi kavitasi pada pompa sentrifugal. Akan tetapi, metode tersebut khususnya pada spektrum getaran tidak menunjukkan hubungan yang jelas antara amplitudo pada spektrum dengan level kavitasi (Tan dan Leong, 2008). Tujuan penelitian ini adalah membagi bentang frekwensi menjadi bentang frekwensi rendah dan bentang frekwensi tinggi pada spektrum getaran dan spektrum envelope. Bentang frekwensi rendah yang digunakan antara 0 sampai $4 \mathrm{kHz}$ dan bentang frekwensi tinggi antara $4 \mathrm{kHz}$ sampai 8,5 kHz. Dengan menggunakan teknik ini diharapkan hubungan antara amplitudo spektrum dan level kavitasi menjadi terlihat lebih jelas.

\section{Metode Penelitian}

Jarrell (2003) menyatakan bahwa terlihat adanya perbedaan dalam spektrum getaran Fast Fourier Transform (FFT) sebelum dan setelah munculnya kavitasi pada pompa sentrifugal. Analisis getaran frekwensi komponen menunjukkan bahwa kenaikan getaran akibat kavitasi muncul pada frekwensi tinggi (lebih dari $1000 \mathrm{~Hz}$ ). Penelitian dalam percobaan tersebut menunjukkan bahwa perubahan yang paling nyata terlihat akan terjadi di frekwensi tinggi. Broadband frequency pada spektrum getaran terkait dengan peningkatan getaran yang disebabkan oleh fenomena kavitasi. Sinyal getaran yang terbatas dalam pengukuran getaran mesin akibat rusak $f(t)$ dapat didekomposisi oleh transformasi fourier $F(w)$, dengan persamaan sebagai berikut pada persamaan 1 dan 2 .

$f(t)=\frac{1}{2 \pi} \int_{-\infty}^{+\infty} f(w) e^{i w t} d w$

Dimana,

$F(w)=\int_{-\infty}^{+\infty} f(t) e^{-i w t} d t$

Dimana $f(t)$ dan $F(w)$ merupakan persamaan transformasi fourier, $f(t)$ dapat didekomposisi menjadi satu kelompok dengan

harmonik $e^{i w t}$.

Koefisien pembeban merepresetasikan amplitudo harmonik pada $F(w) . f(t)$ adalah domain waktu yang mewakili komposisi frekwensi dari proses yang acak, yang diasumsikan bahwa statistiknya tidak berubah seiring berjalannya waktu.

Penelitian ini menggunakan alat uji kavitasi yang dirancang untuk mensimulasikan fenomena kavitasi pada pompa sentrifugal. Empat kondisi operasi pompa akan disimulasikan yaitu kondisi normal (tanpa kavitasi), level kavitasi 1, 2 dan 3 yang berturut-turut adalah kavitasi tingkat awal, menengah dan akhir. Level kavitasi dibuat dengan mengatur katup pada sisi hisap pada alat uji.

Gambar 1 merupakan skema dari alat uji penelitian yang komponen-komponennya adalah pompa sentrifugal monoblock, motor listrik, flowmeter, pressure gauge, vaccum gauge, globe valve, instalasi pipa, tangki penampung air, perangkat data akuisisi dari National Instrument, akselerometer, dan laptop.

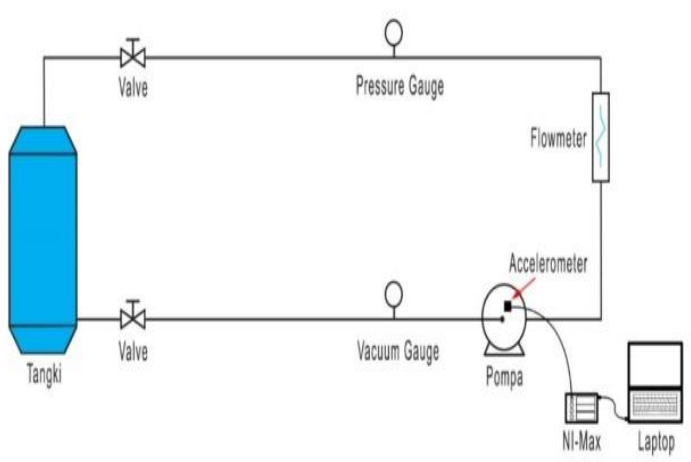

GAMBAR 1. Skema test rig kavitasi 
Sinyal getaran dari masing-masing kondisi operasi pompa direkam oleh sebuah akselerometer yang diletakkan pada rumah pompa di bagian sisi hisap berdekatan dengan lokasi impeller. Perekaman sinyal getaran dilakukan dengan sampling rate sebesar 17066 Hz. Akuisisi sinyal getaran dilakukan sebanyak 300 potong data untuk masing-masing kondisi pompa yang setiap potongnya berdurasi rekaman 10 detik; terdapat jeda 2 detik di antara rekaman dua potong data.

Sinyal getaran setiap potong data dibagi menjadi dua berdasarkan jangkauan frekwensinya yaitu bentang frekwensi rendah, $0-4 \mathrm{kHz}$ dan bentang frekwensi tinggi yaitu 4$8,5 \mathrm{kHz}$. Pembagian sinyal menjadi dua jangkauan ini dilakukan menggunakan property transformasi wavelet yaitu dekomposisi sinyal menggunakan filter.

Sinyal getaran yang telah dibagi menjadi dua bentang frekwensi ditransformasikan kedalam domain frekwensi (spektrum) dan spektrum envelope. Identifikasi kavitasi dilakukan dengan observasi amplitudo pada frekwensi blade pass frequency (BPF) dan harmoniknya.
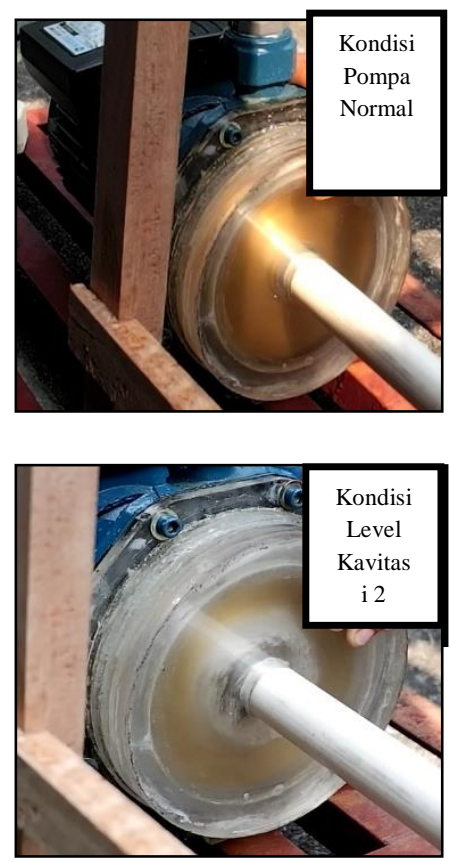

\section{HASIL DAN PEMBAHASAN}

Hasil visualisasi kavitasi pada penelitian ini dapat dilihat pada Gambar 2. Visualisasi tersebut menunjukkan proses terbentuknya kavitasi dalam kondisi normal hingga kavitasi level 3. Dari hasil visualisai tersebut kemudian dilakukan identifikasi fenomena kavitasi menggunakan sinyal getaran pada spektrum getaran dan spektrum envelope.

Plot sinyal getaran domain waktu ditunjukkan pada Gambar 3. Terlihat adanya perbedaan antara sinyal getaran dari pompa kondisi normal dengan kondisi kavitasi pada semua level dimana amplitudo getaran semakin kecil seiring dengan meningkatnya level kavitasi. Namun demikian tidak dapat dibedakan penurunan amplitudo tersebut disebabkan oleh kavitasi atau oleh penyebab yang lain. Perlu dilakukan analisa lebih lanjut dengan menggunakan spektrum getaran dan spektrum envelope pada bentang frekwensi rendah dan bentang frekwensi tinggi sehingga indikator unik kavitasi dapat didentifikasi.
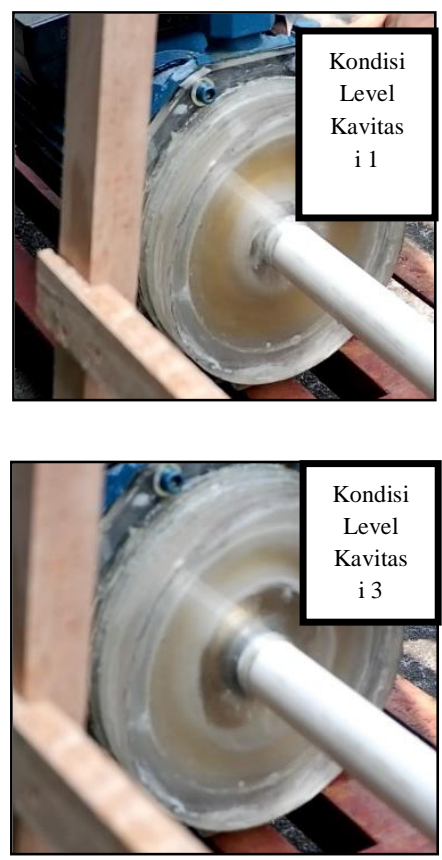

GAMBAR 2. Visualisasi kavitasi 


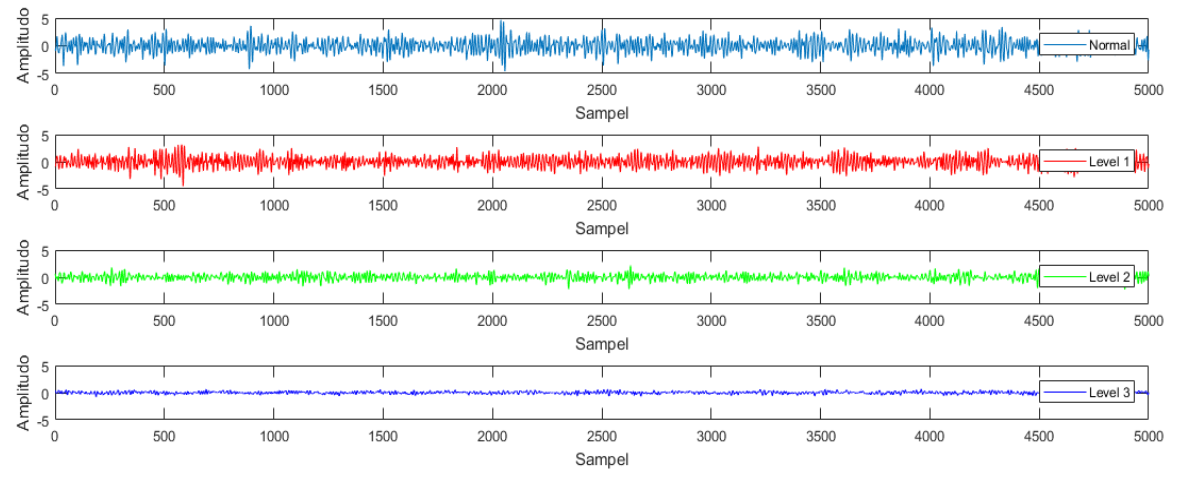

GAMBAR 3. Sinyal getaran dalam domain waktu
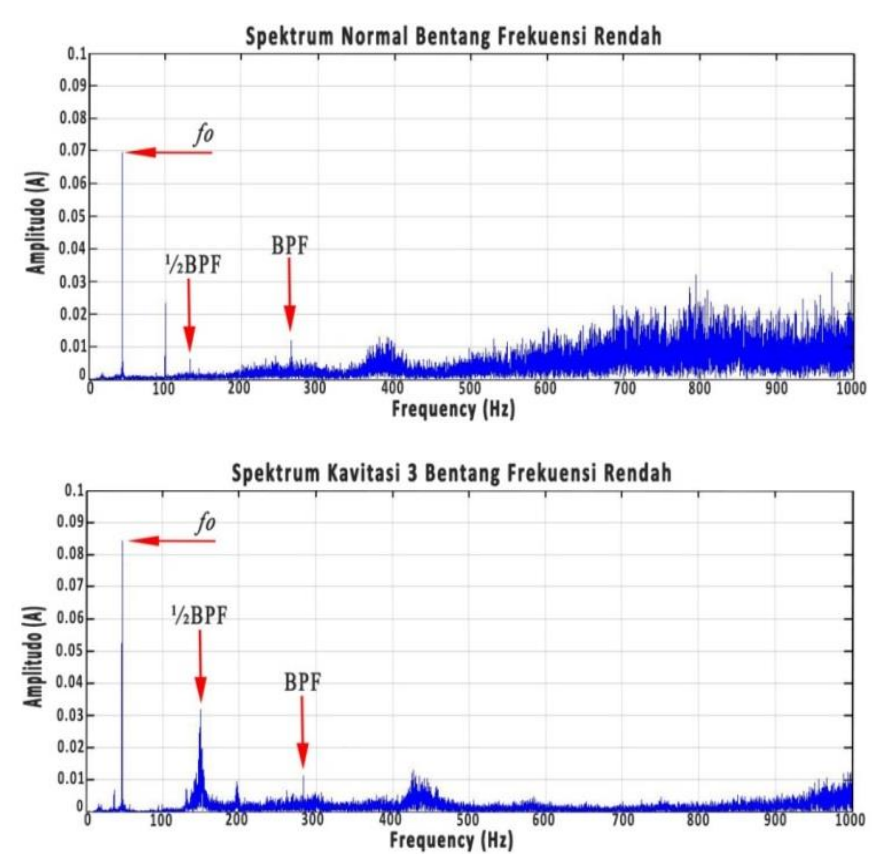

GAMBAR 4. Spektrum bentang frekwensi rendah (0-4 Khz) kondisi normal dan kavitasi level 3

Gambar 4 menunjukkan spektrum frekwensi rendah yang memperlihatkan kenaikan nilai amplitude frekwensi $1 \frac{1}{2}$ BPF pada kavitasi level 3. Kenaikan ini mengindikasikan bahwa level kavitasi yang terjadi semakin besar dibandingkan dengan 2 level kavitasi lainnya. Hal ini terjadi karena jumlah air yang terhisap oleh pompa berkurang secara drastis akibat dari penutupan katup. Fenomena ini menyebabkan gelembung kavitasi terbentuk semakin banyak yang berakibat meningkatkan level getaran impeler sehingga dapat terjadi kelonggaran atau ketidakseimbangan (unbalance) pada komponen. Hal ini dibuktikan oleh peningkatan amplitudo frekwensi $1 / 2$ BPF dan BPF dari spektrum kavitasi level 3 Terlihat pada spektrum bahwa frekwensi harmonik dari $1 / 2$ BPF dan BPF pada spektrum frekwensi rendah kavitasi level 3 mengalami peningkatan amplitudo. Dimana nilai frekwensi dan amplitudo 1/2 BPF sebesar 149,6 Hz dan 0,033 $\mathrm{mV}$. Sedangan frekwensi dan amplitudo BPF nilainya sebesar $283,7 \mathrm{~Hz}$ dan $0,013 \mathrm{mV}$. 

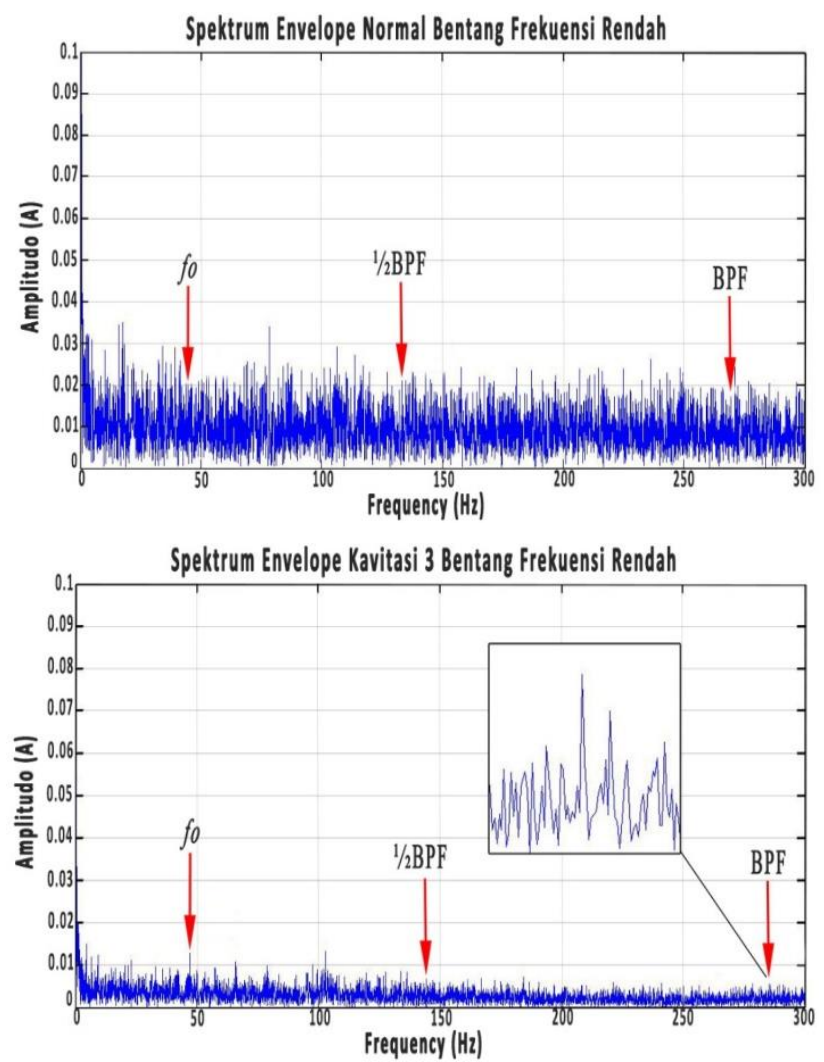

GAMBAR 5. Spektrum envelope bentang frekwensi rendah (0-4 Khz) kondisi normal dan kavitasi level 3

Spektrum envelope frekwensi rendah kondisi normal dan kavitasi level 3 dapat dilihat pada Gambar 5. Spektrum envelope kavitasi level 3 menunjukkan bahwa amplitudo noise mengalami penurunan. Penurunan nilai amplitudo noise pada spektrum envelope kavitasi 3 menunjukkan penurunan level getaran yang terjadi.

Penurunan level getaran disebabkan oleh berkurangnya volume air yang masuk ke impeller walaupun jumlah gelembung udara yang terbentuk semakin banyak. Fenomena ini sesuai dengan pengamatan pada Gambar 3 dimana amplitudo getaran pada domain waktu mengalami penurunan seiring meningkatnya level kavitasi. Namun dapat diamati pada frekwensi fundamental (fo), frekwensi $3 \mathrm{x}$ fo (1/2 BPF), dan $6 \mathrm{x}$ fo (BPF) mengalami kenaikan amplitudo. Hal ini terjadi karena level getaran semakin tinggi akibat dari semakin banyak gelembung udara yang pecah. Spektrum envelope frekwensi rendah hanya berhasil mendeteksi kavitasi level 3 (level lanjut) namun tidak berhasil mendeteksi kavitasi level 1 (level dini). Maka perlu dilakukan proses analisis selanjutnya dengan menggunakan spektrum dan spektrum envelope frekwensi tinggi.

Gambar 6 merupakan perbandingan antara spektrum frekwensi tinggi pompa normal dan kondisi kavitasi. Dapat dilihat pada kedua spektum tersebut bahwa terjadi penurunan nilai amplitudo pada spektrum kavitasi level 1 . Penurunan nilai tersebut juga terjadi pada amplitude harmoniknya.

Frekwensi harmonik pada kedua spektrum merupakan frekwensi harmonik dari frekwensi BPF atau impeler.

Pada spektrum pompa kondisi normal amplitudo tertinggi adalah $0.04 \mathrm{mV}$. Sedangkan pada pompa kondisi kavitasi level 1 nilai amplitudo tertingginya sebesar $0.022 \mathrm{mV}$. Kedua angka tersebut merupakan amplitudo dari impeler atau BPF.

Hasil ini menunjukkan bahwa terjadi penurunan volume air yang dihisap oleh pompa pada kavitasi level 1 sehingga proses terbentuknya kavitasi dapat terjadi pada kondisi tersebut walaupun intensitasnya hanya sedikit. 

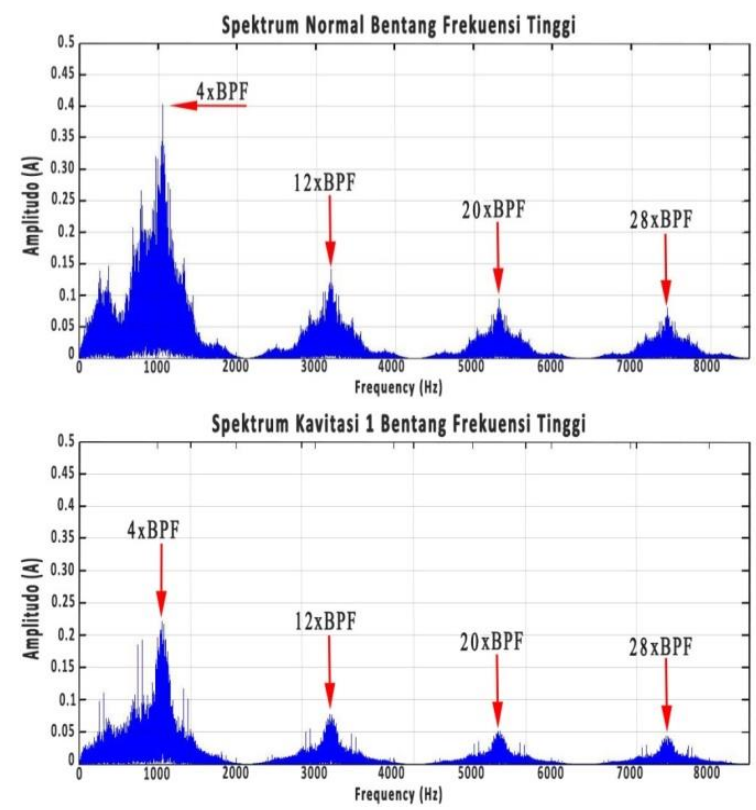

GAMBAR 6. Spektrum bentang frekwensi tinggi $(4 \mathrm{kHz}-8,5 \mathrm{kHz})$ kondisi normal dan kavitasi level 1

Gambar 7 adalah spektrum envelope frekwensi tinggi pompa kondisi normal dan kavitasi level 1. Kedua spektrum envelope tersebut terlihat berbeda dengan spektrum pada Gambar 6 dimana amplitudo pada frekwensi harmonic BSF. lebih mudah diobservasi karena amplitudo dari noise di sekitarnya sudah direduksi.

Amplitudo frekwensi harmonik kavitasi level 1 pada spektrum envelope tersebut menunjukkan penurunan Amplitudo yang menurun merupakan indikasi bahwa terbentuknya gelembung kavitasi dini sudah terjadi. Hal ini disebabkan tekanan yang masuk saat pompa beroperasi dengan kondisi kavitasi level 1 mengalami penurunan tekanan dan volume.

Frekwensi BPF yang memiliki frekwensi sebesar $1067 \mathrm{~Hz}$ merupakan frekwensi dari impeler pompa. Munculnya frekwensi harmonik 4xBPF, 8xBPF, 16xBPF, 24xBPF mengindikasikan peningkatan level getaran yang terjadi ketika pompa beroperasi. Pada spektrum envelope kavitasi level level 1 terlihat bahwa amplitude pada frekwensi harmonik mengalami penurunan. Hal ini mengindentifikasi bahwa kavitasi dini telah terjadi.
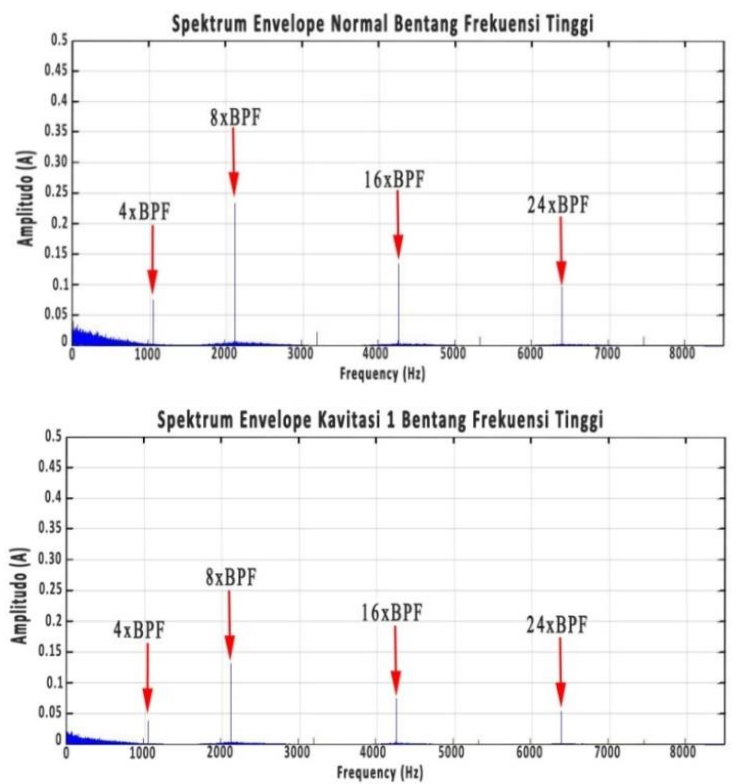

GAMBAR 7. Spektrum envelope bentang frekwensi tinggi $(4 \mathrm{kHz}-8,5 \mathrm{kHz})$ kondisi normal dan kavitasi level 1 
Akselerometer diletakkan sedekat mungkin di posisi komponen pompa yang terdampak oleh fenomena kavitasi yakni pada bagian intake dengan arah axial. Proses terbentuknya gelembung kavitasi disebabkan oleh fluida yang mengalir mengalami penurunan tekanan sampai dibawah tekanan jenuhnya kemudian berbenturan dengan mata impeler dimana fluida tersebut kemudian membentuk pusaran.

Dalam mengamati indikasi terjadinya fenomena kavitasi perlu dilakukan perbandingan antara spektrum getaran dan spektrum envelope pada kondisi pompa normal dengan kavitasi level 1, kavitasi level 2 dan kavitasi level 3. Spektrum getaran dan spektrum envelope yang digunakan untuk mengamati fenomena kavitasi dibagi pada bentang frekwensi rendah dan bentang frekwensi tinggi. Pembagian ini dilakukan agar deteksi kavitasi dapat diamati melalui bentang frekwensi rendah atau bentang frekwensi tinggi. Hasil penelitian menunjukkan bahwa spektrum dan spektrum envelope pada bentang frekwensi rendah dapat digunakan dalam mendeteksi kavitasi level lanjut.

Spektrum pada bentang frekwensi rendah terjadi kenaikan nilai amplitudo secara signifikan pada kondisi pompa kavitasi 3. Hal ini menunjukkan bahwa terjadi kavitasi dengan mengamati nilai amplitudo pada frekwensi fundamental dan frekwensi BPF dan $1 / 2$ BPF Kenaikan nilai amplitudo tersebut dapat disebabkan oleh massa unbalance pada pompa semakin membesar sehingga getaran yang ditimbulkan juga semakin besar.

Namun indikasi kavitasi dini pada spektrum getaran pada bentang frekwensi rendah tidak dapat diamati. Karena terjadinya kavitasi pada spektrum ini hanya terlihat secara jelas pada kondisi kavitasi 3.

Kemudian hasil yang ditunjukkan oleh spektrum envelope dengan bentang frekwensi rendah menunjukkan penurunan nilai amplitudo secara bertahap pada setiap kenaikan level kavitasi. Namun penurunan angka ini tidak dapat menunjukkan secara jelas kavitasi yang terjadi pada pompa. Hal ini disebabkan karena masih terdapat amplitudo noise yang menutupi amplitudo frekwensi fundamental dan frekwensi sudu impeler atau BPF. Sehingga fenomena kavitasi dini maupun lanjut pada spektrum envelope bentang frekwensi rendah tidak bisa menunjukkan terjadinya kavitasi secara akurat.

Sedangkan spektrum pada bentang frekwensi tinggi menunjukkan bahwa terlihat indikasi kavitasi dini pada kavitasi level 1. dimana terjadi penurunan nilai amplitudo frekwensi harmonik BPF. Penurunan nilai amplitudo ini terjadi cukup siginifikan. Hal ini dapat sebabkan oleh jumlah volume air yang terhisap oleh pompa menurun, sehingga fenomena kavitasi mulai terbentuk seiring dengan menurunnya tekanan pada suction pompa ketika saat terjadi kavitasi.

Namun hal yang unik terlihat pada hasil yang ditunjukkan oleh spektrum pada bentang frekwensi tinggi saat terjadi kavitasi level 2 dimana justru amplitudo pada frekwensi harmonik BPF mengalami kenaikan walaupun kenaikan nilai tersebut tidak melebihi nilai amplitudo pada saat pompa kondisi normal. Menurut Ari dkk (2013) peningkatan amplitudo frekwensi poros pompa dapat disebabkan oleh bertambahnya massa unbalance pada impeler pompa yang rusak. Hal ini dapat mengindikasikan bahwa terjadi getaran yang cukup kuat akibat terjadinya kavitasi. Namun getaran tersebut terjadi hanya berlangsung beberapa saat karena pada kondisi kavitasi 3 nilai amplitudo yang ditunjukkan oleh spektrum kembali mengalami penurunan secara signifikan.

Selanjutnya dari hasil yang ditunjukkan oleh spektrum envelope dengan bentang frekwensi tinggi, dapat diamati bahwa penurunan nilai amplitudo terjadi secara bertahap seiring dengan bertambahnya level kavitasi. Pada spektrum envelope bentang frekwensi tinggi terlihat jelas bahwa amplitudo pada frekwensi harmonik BPF mengalami penurunan secara bertahap. Penurunan nilai ampitudo pada frekwensi harmonik BPF disebabkan semakin berkurangnya volume air yang terhisap oleh pompa juga tekanan yang terjadi pada sisi hisap. Berkurangnya volume air yang terjadi secara bertahap ini dapat menyebabkan turbulensi aliran semakin membesar. Membesarnya turbulensi aliran air mengakibatkan tumbukan antara air dengan sudu impeler semakin mengecil. Sehingga getaran yang ditimbulkan juga akan semakin berkurang.

Berdasarkan uraian di atas, kavitasi dini mampu dideteksi melalui spektrum envelope bentang frekwensi tinggi antara 4-8,5 kHz. Hasil menunjukkan bahwa amplitudo pada frekwensi BPF pada kavitasi level 1, sampai 3 mengalami penurunan nilai secara bertahap.

Sedangkan pada spektrum bentang frekwensi rendah hanya mampu menunjukkan terjadinya 
kavitasi pada level kavitasi lanjut yang disebabkan oleh kenaikan nilai amplitudo secara drastis pada frekwensi poros, frekwensi BPF, dan $1 / 2$ BPF. Dimana kenaikan nilai tersebut berasal dari massa unbalance yang diakibatkan oleh fenomena kavitasi dengan level tinggi.

Peningkatan nilai amplitudo pada frekwensi $1 / 2$ BPF yang teramati baik pada spektrum bentang frekwensi rendah dan tinggi mejadi indikator yang sangat penting dalam mendeteksi kavitasi. Hal ini serupa dengan yang disimpulkan oleh Tan dan Leong (2008) yang menyatakan bahwa kenaikan amplitudo pada frekwensi $1 / 2$ BPF disebabkan oleh pecahnya gelembung kavitasi secara dini sebelum terbentuk satu buah siklus putaran impeler.

\section{KESIMPULAN}

Metode deteksi kavitasi dengan menggunakan bentang frekwensi rendah $0-4 \mathrm{kHz}$ pada spektrum dan spektrum envelope hanya mampu mendeteksi kavitasi lanjut khususnya pada spektrum Nilai amplitudo yang ditunjukkan pada frekwensi fundamental, $1 / 2$ BPF dan BPF ketika pompa mengalami level kavitasi 3 terjadi kenaikan amplitudo yang disebabkan oleh massa unbalance yang besar. Dimana kavitasi dapat diidentifikasi melalui getaran yang terjadi akibat unbalance pada poros dan juga impeler pompa. Sedangkan pada spektrum envelope dengan bentang frekwensi rendah tidak mampu mengidentifikasi terjadinya kavitasi dini maupun lanjut secara akurat. Hal ini disebabkan karena pada spektrum envelope terdapat noise yang menutupi amplitudo fundamental dan $1 / 2$ BPF juga BPF, baik pada kondisi pompa normal maupun pada variasi level kavitasi.

Spektrum dan spektrum envelope bentang frekwensi tinggi $4-8,5 \mathrm{kHz}$ dapat mendeteksi terjadinya kavitasi dini. Kedua spektrum tersebut menunjukkan penurunan nilai amplitudo pada frekwensi harmonik impeler (BPF). Khususnya pada spektrum envelope, penurunan amplitudo dapat teramati dengan lebih jelas. Nilai amplitudo tersebut mengalami penurunan secara bertahap seiring dengan bertambahnya level kavitasi. Hal ini menunjukkan bahwa semakin besar kavitasi yang terjadi maka nilai amplitudo pada frekwensi sudu impeler yang ditimbulkan oleh pecahnya gelembung kavitasi akan semakin kecil.

\section{DAFTAR PUSTAKA}

Albraik, A., Althobiani, F., Gu., F., \& Ball, A. (2012). Diagnosis of Centrifugal Pump Fault Using Vibration Methods. Journal of Physics. Conf. Ser. 364

Al-Hashmi, S., Gu., F., Li, Y., Ball, A., Fen, T., Lui, K. (2004). Cavitation Detection of a Centrifugal Pump Using Instantanous Angular Speed. ASME 7th Biennal Conference on Engineering System Design and Analysis (hal. 106-110). American Society of Mechanical Engineer.

Ari, A., Susilo, D., \& Arifin, Z. (2013). Deteksi Kerusakan Impeler Pompa Sentrifugal Dengan Analisis Sinyal Getaran. MEKANIKA 11(2), 116-122

Avellan, F. (2004). Introduction to Cavitation in Hydraulic Machinery. The 6th International Conference on Hydraulic Machinery and Hydrodynamics. Timisoara, Romania.

Contreras, L., Modi, R., \& C, P. A. (2002). Integrating Simulation Modeling and Equipment Condition Diagnostig for Predictive Maintenance. Proceedings of The Year 2002 Winter Simulation Conference, 1289-1296.

Farhat, M. (1996). Cavitation Monitoring of Hydraulic Machines by Vibration Analysis Swiss Federal Institute of Technology. (Doctoral Thesis)

Isranuri, R., \& Irwansyah. (2012). Simulasi Karakteristik Bubble Sebagai Indikasi Awal Terjadinya Fenomena Kavitasi Dengan Menggunakan Sinyal Vibrasi Pada Pompa Sentrifugal Dengan Menggunakan CFD. Jurnal Dinamis.1(1), 1-9

Jarrel, D. (September 2003). Analysis of Vibration and Accoustic Data for Ice Harbour Dam Axuiliry Water Supply Pump. Submitted to the U.S Army Core of Engineers.

Kaye, M. (2000) Cavitation Monitoring of Hydraulic Machines by Vibration Analysis. (Doctoral Thesis)

Kaye, M., \& Farhat, M. (2003). Classification of Cavitation in Hydraulic Machines Using Vibration Analysis, Proceedings 
of the 21th IAHR Symposium on Hydraulic Machinery and Systems, Lausanne, Switzerland.

Pouya, S., Posthan, J., \& Hamed, S. (2017). Cavitation Detection in Centrifugal Pump Using Pressure Time-Domain Features. Turkish Journal of Electrical Engineering and Computer Science.

Soyama, H., Kato, H., \& Oba, R. (1992). Prediction of Erotion Cavitation at Impeller Centrifugal Pump. Proceedings of the Institution of Mechanical Engineers. Cambridge, Robinson College.

Tan, C. Z., \& Leong, S. M. (2008). An Experimental Study of Cavitation Detection in a Centrifugal Pump Using Envelope Analysis. Journal of System Design and Dynamics. 2(1), 274-285

Yohana E., \& Majiid, M. F. (2016). Analisis Numerik dan Validasi Kasus Kavitasi Pompa Sentrifugal Mission Magnium I Menggunakan CFD. ROTASI. 18(3), 89-92

Zouari, R., Sieg-Zieba, S., \& Sidahmed, M. (2004) Fault Detection Systems for Centrifugal Pumps Using Neural Networks and Neuro-fuzzy Techniques. Surveillance 5 CETIM Senlis.

PENULIS:

Berli Paripurna Kamiel

Program Studi Teknik Mesin, Fakultas Teknik, Universitas Muhammadiyah Yogyakarta, Jalan Brawijaya, Tamantirto, Kasihan, Bantul, Yogyakarta.

email: berlikamiel@umy.ac.id

Deby Arikh Nasaka

Program Studi Teknik Mesin, Fakultas Teknik, Universitas Muhammadiyah Yogyakarta, Jalan Brawijaya, Tamantirto, Kasihan, Bantul, Yogyakarta.

Bambang Riyanta

Program Studi Teknik Mesin, Fakultas Teknik, Universitas Muhammadiyah Yogyakarta, Jalan Brawijaya, Tamantirto, Kasihan, Bantul, Yogyakarta.
Azhim Asyratul

Program Studi Teknik Mesin, Fakultas Teknik, Universitas Muhammadiyah Yogyakarta, Jalan Brawijaya, Tamantirto, Kasihan, Bantul, Yogyakarta. 